\title{
scripted
}

Volume 14, Issue 2, December 2017

\section{Editorial: A Year of Change and Transition}

\author{
Edward S. Dove* and Jiahong Chen ${ }^{* *}$
}

\section{(ㄷ) (1) $(9)$}

(C) 2017 Edward S. Dove and Jiahong Chen Licensed under a Creative Commons Attribution-NonCommercial-

NoDerivatives 4.0 International (CC BY-NC-ND 4.0) license

DOI: 10.2966/scrip.140217.164

\footnotetext{
* Editor-in-Chief, SCRIPTed

** Managing Editor, SCRIPTed
} 
This has been a year full of new developments - not only for SCRIPTed, but also in the fields of law covered by the journal. With remarkable breakthroughs in such areas as artificial intelligence, Big Data, and smart technologies, ongoing debates surrounding the social, political, and ethical implications - as well as the legal regulation of these advances - are becoming ever-more heated. We believe the contents of this Issue 14:2 will give our readers a richer sense of and appreciation for these developments, particularly from a global perspective.

In this issue, we are delighted to present four robust, interdisciplinary Articles that represent the latest research achievements in their fields. Douglas Walton and Thomas F. Gordon illustrate the promise of artificial intelligence in argument invention by showing how two recently developed computational tools function in the process of finding arguments for or against a claim. From a classical criminal case outlined in Cicero's De Inventione to a hypothetical example of software copyright licensing, the article explains the ways in which argument invention may be put to use in legal contexts.

The other articles address privacy and data protection, which serves as a reminder that 2017 marks a year of transition for data protection in Europe: the EU General Data Protection Regulation 2016/679, one of the most important pieces of legislation in the history of the EU, will come into effect in May 2018. Lisa van Dongen and Tjerk Timan explore the privacy implications as smart technologies gain popularity. They argue that the current concept of "home" under Dutch law falls short on tackling the new privacy threats arising from the use of smart devices.

In a different context and jurisdiction, Teresa Scassa expands on the ramifications of the practices of Geofeedia - a US company reportedly helping law enforcement analyse georeferenced data on social media for surveillance purposes. Given the limitations of the privacy approach under US and Canadian doctrines, Scassa advocates an alternative, normative approach that calls for 
transparency in policy, oversight, and enforcement of police use of social media data analytics.

Minke D. Reijneveld employs the concept of Quantified Self to theorise the potential threats of apps that assist data collection about oneself. Such threats are unfolded in terms of the internal and external restriction of individual freedom. An assessment of the GDPR is carried out in this light, with the conclusion that while the GDPR has made certain improvements in protecting external freedom, the issues of internal freedom remain largely unaddressed.

In addition to these full-length Articles, an Analysis piece and a Legislative Comment are also included in this issue. In the analysis piece by Shawn Harmon, Abbe Brown, Sita Popat, Sarah Whatley, and Rory O'Connor, the notions of identity and integrity are examined against legal regimes, whereby the insufficient engagement of law with the person is revealed. The commentary by Andrew Cormack on the draft EU ePrivacy Regulation highlights the seeming shift of compliance burden regarding use of cookies from websites to web browsers, and the Regulation's interactions with the GDPR. Lastly, readers will find a selection of Book Reviews that cover the wide areas of intellectual property, information technology, and medical law.

As regards SCRIPTed, we are also at moment of change and transition. Long-time readers of this journal will observe that we have introduced a new look and style for Volume 14, which was highlighted in the editorial of the last issue. We hope you find these new changes refreshing and helpful for your reading. Also, a new team - with some returning members - will soon begin to prepare for the next, fifteenth volume of the journal as we march to 2018. While our Consulting Editors, Advisory Board members, and Supervising Editors (Gerard Porter, Nicolas Jondet, and Smita Kheria) will be staying on the Editorial Board, a new group of editors will be taking over the day-to-day operation of journal: Jiahong Chen as the Editor-in-Chief and Book Reviews Editor, Annie 
Sorbie as the Managing Editor, Laurence Diver as the Technical Editor and Social Media Editor, and an enthusiastic team of copyeditors and postgraduate students from Edinburgh Law School serving as Assistant Editors. What remains unchanged is our goal to provide a high-quality, peer-reviewed, open-access platform for scholars all over the world to share and to acquire knowledge in the broadest areas of law, technology, and society.

We hope you enjoy Issue 14:2 of SCRIPTed, and we wish everyone an enjoyable holiday and a wonderful new year. 